\title{
STRATEGI KEANDALAN PELAYANAN PADA PT. BPRS SARANA PRIMA MANDIRI
}

\author{
Subaidaa \\ Mansur ${ }^{b}$ \\ Ridan Muhtadic \\ a,b,c Program Studi Ekonomi Syariah, STAI Miftahul Ulum, Pamekasan. \\ Email: subaidahsamsiyeh@gmail.com; elcmansur@gmail.com; ridanmuhtadi@gmail.com
}

\begin{abstract}
Introduction: The purpose of this study was to determine the service reliability strategy in serving customers. This service strategy is a supporting factor for the marketing activities of all products in order to achieve customer satisfaction.

Methods: The research methodology used is a qualitative descriptive. Data collection techniques using observation documentation interviews.

Results: The results of this study indicate that the reliability of this service is quite good and in accordance with its field. However, the SPM Pamekasan Bank does not have an ATM. In overcoming these shortcomings SPM banks by improving service quality by using service reliability. So that customers feel satisfied and even become loyal customers. So in this case the SPM Pamekasan Bank is one of the services that is in accordance with the expectations of the community.
\end{abstract}

Keywords: Service reliability strategy, Customer satisfaction.

\section{PENDAHULUAN}

Bank Syariah ini diyakini sebagai bank Islami. ${ }^{1}$ Akan tetapi kata Syariah ini dianggap sebagai sebuah nama bank bagi masyarakat jawa timur. Seperti Bank SPM, serta Mandiri, dan sebagainya. Bank Syariah bagi mereka adalah merupakan sebuah lembaga ekonomi politik yang didirikan atas dengan dasar sentimen agama yang dengan tujuan membela salah satu agama. Jadi masyarakat jawa pada umumnya dan jawa timur yang dibutuhkan khususnya, bukan embel-embel agama, akan tetapi mutu pelayanan yang praktis, efisien serta humanis. Dengan kata lain, Bank syariah ini harus lebih manusiawi dari pada bank konvensional. ${ }^{2}$

\footnotetext{
${ }^{1}$ Muslikhin, M., Kinanti, R. A., Muhtadi, R., \& Fudholi, M. PEMERIKSAAN EMPIRIS PADA PENGARUH KINERJA SOSIAL TERHADAP PROFITABILITAS DI BANK SYARIAH. Ulumuna: Jurnal Studi Keislaman, 6(1), 2020. $72-$ 84. Lihat juga, Rosyadah, P. C., Arifin, N. R., Muhtadi, R., \& Safik, M. (2020). Factors That Affect Savings In Islamic Banking. AL-ARBAH: Journal of Islamic Finance and Banking, 2(1), 33-46.

${ }^{2}$ Mansur, M. BANK SYARIAH: Antara Labelisasi dan Pemberdayaan Ekonomi Masyarakat. Ulumuna: Jurnal Studi Keislaman, 4(1), 2018. 54-70.
} 
Dalam dunia usaha yang sekarang ini persaingan semakin ketat, para pelaku usaha baik persekutuan ataupun perorangan, didalam perusahaan tersebut pasti mempunyai faktor yang bisa dijadikan senjata oleh perusahaan agar memenangkan persaingan dengan pesaing dunia bisnis. Akan tetapi perusahaan yang sudah berusaha bersaing sehingga mampu memberikan yang terbaik bagi pelanggan sehingga belum tentu dapat menjamin keberhasilan dalam usaha pencapaian serta tujuan perusahaan tersebut. Karena setiap pelanggan pasti mempunyai keinginan atau selera yang berbeda-beda, maka begitu pula perusahaan juga mempunyai strategi pelayanan yang berbeda-beda juga. $^{3}$

Strategi pelayanan salah satu yang merupakan faktor yang sangat penting dalam meningkatkan kepuasan nasabah atau meningkatkan citra perusahaan itu sendiri karena perusahaan bank sebagai penyedian jasa keuangan yang sangat tergantung pada nasabah atau pelanggan yang memakai jasanya. Sehingga diperlukan sebuah strategi keandalan pelayanan agar nantinya nasabah atau pelanggan tidak berpindah kepelayanan perusahaan jasa lain. Strategi keandalan pelayanan disini merupakan suatu kemampuan untuk memberikan pelayanan yang sesuai dengan yang sudah dijanjikan dan terpercaya, memberikan kemampuan pelayanan yang sudah dijanjikan dan memuaskan untuk mendukung karyawan serta memberikan pelatihan pendidikan untuk meningkatkan kepuasan nasabah. ${ }^{4}$

Bank SPM pamekasan merupakan lembaga yang bertujuan untuk menyelamatkan masyarakat dari praktek ekonomi yang tidak sesuai dengan prinsip syariah. ${ }^{5}$ Sehingga masyarakat yang awalnya menabung di bank konvensional yang didalamnya terdapat bunga, maka nasabah berpindah pada Bank SPM yang terbebas dari riba. Hal tersebut juga didukung dari segi pelayanan yang diberikan bank spm dimana untuk segi pelayanan yang dilakukan oleh bank spm yaitu pihak bank mendatangi nasabah yang ingin menabung ataupun membayar angsuran. Kepuasan pelayanan terhadap pelanggan merupakan suatu respon yang positif sehingga memperlihatkan rasa senang dan suka terhadap pelayanan yang telah diberikan oleh bank spm. Hal ini bisa mempertahankan dan dapat menciptakan efektivitas dan efesiensi bak spm tersebut. Sehingga nasabah akan tetap setia dan tidak akan pindah pada bank lain.

Penelitian yang dilakukan oleh Nur Ali dengan judul Penilaian yang mengenai kinerja teller pada bank muamalat Indonesia tbk KCP Metro. Metode yang digunakan metode kualitatif deskriptif seorang penulis dalam mengumpulkan data menggunakan teknik analisis data. Hasil penelitian adalah pelayanan yang diberikan kepada nasabah belum mendapatkan sasaran yang ditentukan oleh manajemen bank tersebut, akan

\footnotetext{
${ }^{3}$ Aliyah, Strategi Pelayanan PT. Bank Bukopin TBK Dalam Meningkatkan Loyalitas Nasabah di Makassar ( Skripsi, Universitas Hasanuddin Makassar,2012),hal,1-2

${ }^{4}$ Nur Dwi Jayati, "Kualitas pelayanan(Reabilitity, Responsiveness, Assurance, Emphaty, Tangibles) Di Legend Premium Coffee Yogyakarta", (Skripsi, UN Yogyakarta, 2016), 19

${ }_{5}^{5}$ Ikbal,Wawancara, Selaku Funding di Bank SPM Pamekasan Pada Tanggal 10- Oktober-2020
} 
tetapi yang harus ditingkatkan beberapa transaksi supaya mendapatkan sasaran yang sudah ditetapkan oleh manajemen PT Bank Muamalat tersebut. ${ }^{6}$

Sedangkan fenomena yang ada di Bank SPM masalah utama bersaingya pelayanan. Yang mana bersaingnya pelayanan kalau bicara tentang produk mungkin tidak jauh beda dengan bank yang lain atau koperasi tapi bersaing dalam pelayanannya apalagi karakter orang Madura atau masyarakat ataupun nasabah pengennya tidak ribet, tidak nunggu lama dan pengen yang instan. ${ }^{7}$

Dan kedua tidak ada ATM karena izinnya sulit sekelas BPRS belum ada ATMnya sebenarnya tempatnya sudah ada tapi terkendala dengan izin. ${ }^{8}$ Oleh sebab itu masyarakat atau nasabah perlu untuk mengetahui bagaimana pelayanan keandalan yang diberikan oleh Bank SPM karena sebenarnya antara bank keuangan syariah pasti memiliki keunggulan tersendiri dari segi pelayanannya. Hal tersebut dapat menjadi tolak ukur bagi nasabah untuk tetap menjadi nasabah pada Bank SPM tersebut.

Berdasarkan latar belakang yang telah dipaparkan diatas, maka penulis disini bertjuan untuk dapat mengetahui bagimana Strategi Keandalan Pelayanan pada Bank SPM Pamekasan.

\section{LITERATURE REVIEW}

\section{Strategi}

1). Pengertian srtategi

Strategi adalah langkah langkah yang dilakukan oleh seorang pembisnis atau seorang perusahaan untuk mencapai sasaran yang telah ditentukan oleh seorang pembisnis tersebut. ${ }^{9}$ Strategi diidentik dengan cara, didalam perusahaan harus menerapkan strategi yang mampu dan menjadi faktor terhadap perusahaan tersebut supaya sesuai dengan harapan yang baik bagi perusahaan.

2). Faktor faktor strategi

Strategi suatu yang harus jelas dan berhasil karena membimbing organisasi terhadap tujuannya. Oleh karena itu rancangan strategi menunjukkan faktor-faktor penentuan strategi diantaranya:

a. Lingkungan

Lingkungan ini tidak terletak pada keadaan tetap yang selalu berganti atau berubah. Perubahan berlangsung berdampak sangat luas terhadap seluruh sendi kehidupan manusia. Masyarakat dan individu tidak hanya kepada sistem berfikir akan tetapi juga kebiasaan dan tingkah laku, pandangan dan kebutuhan hidup.

b. Lingkungan Organisasi

${ }^{6}$ Nur Ali, Penilaian Kinerja Teller Pada Pt. Bank Muamalat Indonesis Tbk. KCP Metro ,(Skripsi: Institut Agama Islam Negri, Metro, 2017)

7 Ikbal, Wawancara Selaku funding Di Bank SPM Pamekasan Pada Tanggal 22-Oktober-2020

8 Ikbal, Wawancara 22-Oktober-2020

${ }^{9}$ Kasmir Kewirausahaan ,(Jakarta:Pt Raja Gransindo Persada, 2006), hlm.171 
Yang mana lingkungan organisasi melewati seluruh kebijakan organisasi dan sumber daya yang ada.

c. Kepemimpinan

Yaitu seseorang yang mengambil keputusan yang tinggi dan karena itu pemimpin harus menilai kemajuan didalam lingkungan internal ataupun eksternal. ${ }^{10}$

\section{Keandalan}

1). Pengertian Keandalan merupakan kemampuan yang ada pada diri seseorang yang berkaitan tentang wawasan, pengatahuan, ketarampilan dan diantara lain. ${ }^{11}$

- Mempunyai pengatahuan yang selaras dibidang tugasnya

- Mempunyai keterampilan yang sesuai dibidang tugasnya

- Mempunyai daya kreativitas yang memang cukup baik

- Paham terhadap cara berkomonikasi dengan baik

- Kemudian paham tentang pengatahuan serta dasar hubungan interpersonal dan psikologis sosial

- Dan harus mampu mengendalikan emosi.

Dimensi Pelayanan keandalan yaitu suatu dinamika yang merupakan sangat penting dalam suatu kerja organisasi. Keandalan merupakan bentuk ciri khas ataupun karakteristik yang mempunyai prestasi kerja yang sangat tinggi dari pegawai. Keandalan Pelayanan dapat dilihat dari pelayanan yang diberikan dan yang sesuai dengan pengatahuan yang dimiliki, keandalan yang menguasai pada bidang kerja yang diterapkan, dalam keandalan penguasaan bidang kerja yang sesuai dengan pengalaman yang ditunjukkan serta keandalan ini menggunakan teknologi kerja. ${ }^{12}$

\section{Pelayanan}

Pengertian Pelayanan adalah suatu kegiatan yang diberikan oleh suatu pihak kepada pihak lain yang pada awalnya tidak tampak serta tidak mengakibatkan terjadinya pemindahan kepemilikan. ${ }^{13}$ Pelayanan terhadap Pelanggan yang melihat dari latar belakang karyawan, edukasi pengatahuan, adat dan istiadat budaya, hal tersebut agar pelayanan menjelma menjadi berkualitas serta mempunyai keseragaman bagi para karyawan. Maka hal tersebut diperlukan sebuah pengatahuan tentang dasar-dasar pelayanan secara mendalam.

Adapun pelayanan yang baik diantaranya:

a) Mempunyai kepribadian yang baik

b) Prasarana dan sarana yang tersedia yang baik

c) Dan harus bertaggung jawab kepada setiap nasabah

10 S.P Siaga, Manejemen Modern, (Jakarta:Masagung, 1994),cet. Ke-2,hlm.9.

11 Atep Adya Barata, Dasar-Dasar Pelayanan Prima, (Jakarta: PT Elex Media Kompotindo Kelompok Gramedia, 2003),hlm 209-210

${ }^{12}$ Sunyoto, Hamingpraja, Jaminan kualitas pelayanan konsumen. Penerbit Liberty, Yogyakarta 2004, hal 16. ${ }^{13}$ H.M Nasrullah yusuf, Strategi Membangun Nilai Jasa Dan Kepercayaan Pelangga.n (Yogyakarta 2014 Ed1), hIm. 16 
d) Mampu berbicara dengan baik

e) Dan melayani dengan tepat dan cepat

f) Kebutuhan nasabah harus mampu memahami serta harus memberikan kepercayaan kepada nasabah.

\section{Kualitas Pelayanan}

Didalam perekonomian Indonesia berkembang khususnya dibidang jasa harus mampu menciptakan persaingan yang ketat terkecuali pada perbankan, dan tidak bertumpu pada produk akan tetapi kepada pelayanan dan karena itu suatu perusahaan harus mampu menciptakan atau memberikan pelayanan yang baik. ${ }^{14}$

Manajemen kualitas total, Tenner De Toro menyediakan tiga prinsip utama dalam TQM. ${ }^{15}$ Yang mana tiga hal tersebut adalah:(a) Fokus pada pelanggan. Intinya adalah perhatian terhadap sebuah organisasi ataupun kebiasaan terhadap nasabaha atau pelanggannya baik itu secara internal ataupun secara eksternal. Adapun kualitas ini didasarkan pada konsep bahwa setiap seseorang mempunyai nasabah. Harapan serta Keinginan nasabah itu harus terpenuhi setiap saat. Oleh sebab itu, dalam mengetahui minat nasabah, harus dilakukan sejumlah analisis supaya tidak salah langkah. (b)Perbaikan proses berkelanjutan. Dalam konsep peningkatan kualitas ini berkelanjutan mulai dari anggapan bahwa hasil kerja itu merupakan penambahan dari susunan langkah kerja yang saling terikat sehingga timbul keluaran. Perhatian yang secara terus menerus pada setiap langkah didalam proses kerja adalah hal yang salah satu harus digunakan dalam mengurangi keluaran yang berbeda dan meningkatkan kepercayaan. Tujuan perbaikan pertama dari berkelanjutan adalah proses terpercaya dalam arti output yang didapatkan setiap saat serta akan sama dan sesuai dengan standar yang ditetapkan. Jika perbedaan output sudah dikecilkan akan tetapi hasilnya masih belum diterima, tujuan kedua dari perbaikan proses adalah rancangan ulang proses produksi sehingga diperoleh hasil yang lebih baik yang sesuai dengan harapan nasabah. (c) Keterkaitan total. Pendekatan ini dimulai dengan adanya pimpinan yang aktif dari manajemen senior yang meliputi upaya didalam melakukan keahlian yang dimiliki oleh karyawan organisasi supaya mendapatkan kelebihan bersaing dipasar. Karyawan di setiap level adalah dilengkapi dalam untuk meningkatkan hasil kerja dengan bekerja sama dalam struktur kerja yang elastis didalam penyelesaian masalah, serta memperluas proses, dan memberikan kepuasan terhadap nasabah. Adapun, mitra kerja yang di luar harus berpartisipasi secara aktif serta bekerja dengan karyawan yang berpendidikan untuk member mamfaat terhadap organisasi.

\footnotetext{
${ }^{14}$ Adi S. Widjojo dan Weman Suardy, Analisis strategi pelayanan Oleh Front Liner Dan Pengaruhnya Terhadap Kepuasan Nasabah PT. Bank Central Asia TBK Capen Mayor Okin, Jurnal Ilmiah Kesatuan, No. 02, Vol. 1, Oktober 2009STIE Kesatuan, hlm. 1

${ }^{15}$ Ervicaninda Herry dkk., "Total Quality Management Development and Sharia Governance Efforts in Sharia Micro Financial Institutions to Improve Market Share," IJIEEB: International Journal of Integrated Education, Engineering and Business 2, no. 1 (2019): 27-35, https://doi.org/10.29138/ijieeb.v2i1.809
} 
Menurut konsep Serqual untuk memberikan pelayanan jasa yang baik terdapat lima dimensi yaitu:

\section{a). Berwujud}

Atau yang dikenal sebagai bukti fisik yaitu berupa fasilitas fisik atau perlengkapan dan komonikasi sebagai sarana, dan ini harus diperhatikan karena ini snagat penting dan akan menjadi pertimbangan terhadap pelanggan untuk memilih suatu produk.

b). Keandalan

Maksud Keandalan adalah suatu kemampuan untuk memberikan pelayanan yang sesuai dengan yang sudah dijanjikan dan terpercaya. serta memberikan pelatihan pendidikan untuk meningkatkan kepuasan nasabah. Keandalan adalah bentuk yang merupakan ciri khas ataupun karakteristik yang mempunyai prestasi kerja yang sangat tinggi dari pegawai.

c). Ketanggapan

Ketanggapan atau daya tanggap adalah minat para karyawan untuk membantu para pelanggan dan memberikan pelayanan yang tanggap oleh karena itu pihak manajemen harus mendukung dan memberikan motivasi agar seluruh karyawan akan lebih baik dan mendapatkan imbalan yang sesuai dengan skilnya.

d). Jaminan

Yang dimaksud jaminan adalah melayani nasabah harus mempunyai pengetahuan dan skill serta kesopanan dan yang penting aman dan nyaman, dan hal ini sangat penting supaya nasabah tidak ragu untuk melakukan transaksi dan tepat sasaran.

e). Empati

Empati adalah komonikasi yang baik dan sangat perhatian dan merasakan atas kebutuhan pelanggan. Untuk staf-staf perusahaan dalam mengelola waktu harus tepat sehingga konsumen jika menghubungi akan mudah, untuk memahami pelanggan dan mampu kerja sama dalam suatu hubungan yang baik.

\section{Strategi Mempertahankan Kepuasan Nasabah}

Mengenai layanan pelanggan ataupun kepuasan nasabah ini mengenai kreativitas. Yang mana kreativitas organisasi jasa memungkinkan menangani serta dalam memecahkan masalah-masalah yang sedang dihadapi ataupun yang akan dihadapi dalam praktik bisnis sehari-hari. Dalam untuk mewujudkan serta mempertahankan nasabah atau pelanggan, maka organisasi jasa harus melakukan empat hal. ${ }^{16}$

1. Harus mengenali siapa pelanggannya

2. Memahami dengan tingkat harapan nasabah atas kualitas

3. Harus mengerti strategi kualitas pelayanan pelanggan

\footnotetext{
${ }^{16}$ M. Hamdani Pratama, Strategi Meningkatkan Kualitas Pelayanan Publik ( Studi Deskriptif tentang strategi UPTD Pengujian Kendaraan Bermotor Tandes Kota Surabaya Dalam Meningkatkan Kualitas Pelayanan Pengujian Kendaraan Bermotor ) Jurnal kebijakann dan manajemen publik Volume 3, No3, Septemberdesember hal-95
} 
Dan memahami pengukuran siklus serta umpan balik dari kepuasan nasabah atau pelanggan.

\section{METODE PENELITIAN}

Peneliti menggunakan metode penelitian yang bersifat deskriptif kualitatif. ${ }^{17}$ yang mana peneliti melakukan wawancara tidak hanya satu kali untuk mengatahui apa yang diinginkan, dan data yang diperoleh peneliti ini berbasis kata-kata. Teknik Pengumpulan Data yang dilakukan oleh peneliti menggnakan observasi, wawancara, dan dokumentasi. Peneliti melaksanakan observasi yang secara langsung pada Bank Syariah SPM. Data yang didapat tidak berupa angka melainkan berupa kata-kata tertulis.Yang mana peneliti melakukan wawancara yang mengenai judul yang diambil oleh peneliti. Peneliti ini berfokus kepada strategi keandalan pelayanan. Keandalan pelayanan di Bank SPM ini memiliki daya kreativitas, sesuai dengan bidangnya, mempunyai wawasan, pengatahuan, ketrampilan. Peneliti ini mengadakan dialog bersama dengan salah satu karyawan yang adan di Bank SPM yaitu Bapak IKbal yang selaku sebagai kasi funding.Dokumentasi, Peneliti mengumpulkan data yang dengan melihat browser, Data-Data serta juga peraturan peraturan yang telah ditentukan di bank SPM. dan salah satu peraturan di bank spm dilaksanakan briving pada jam 08:00 dan juga ada kegiatan rutin bagi-bagi sedekah kepada masyarakat disekitar bank SPM pada hari jumat. Analisis Data, sebelum peneliti terjun kelapangan peneliti ini harus belajar telebih dahulu teori yang dibutuhkan oleh peneliti untuk menganalisis data,pengumpulan data sehingga pengelompokan data peneliti tidak sulit. Peneliti ini menelaah serta mepersiapkan teori yang diperlukan di lapangan yang bisa dijadikan teori.

\section{HASIL DAN PEMBAHASAN}

\section{Sejarah PT. BPRS Sarana Prima Mandiri}

PT BPRS Sarana Prima Mandiri dikenal dengan sebutan PT.BPRS SPM. Yang berdiri pada tahun 2008 dengan nama pertama PT .BPRS Sarana pamekasan membangun. Dan pada tahun 2011 BPRS SPM akan membangun kantor cabang, sehingga dewan komisaris ini merancang untuk merubah nama sarana Pamekasan Membangun menjadi Sarana Prima Mandiri. Dan setelah melakukan musyawarah secara bersama para pemilik saham, yang akhirnya diajukan izin perubahan nama kepada MENKUM ,HAM dan Bank Indonesia yang mana dilakukan perubahan nama oleh salah satu notaris pada bulan april. Dan pada tanggal 16 novembrer 2010.

Sehingga pada akhirnya perubahan nama bank tersebut itu disetujui oleh MAHKAMAH dan HAM No AHU 32605 AH.01.02. pada tanggal 30 juni 2011. Akan tetapi pada tanggal 12 maret 2012 dengan penggunaan nama baru tersebut ini tidak dapat izin untuk sementara oleh bank Indonesia karena alasannya pengguna nama tersebut masih

${ }^{17}$ Lexy j, Moleong, Metodologi penelitian kualitatif ( Diterbitkan oleh PT REMAJA ROSDAKARYA Cetakan 31, 2012) 
belum keluar. Oleh sebab itulah, PT BPRS Sarana prima mandiri menggunakan nama asal atau semula. Dan setelah dua bulan berselang yang tepatnya pada tanggal 11 mei 2012 ini surat izin oprasionalnya keluar. ${ }^{18}$ Dan saat ini memiliki dua cabang yang berada di Kabupaten Bangkalan dan Sumenep.

\section{Strategi Keandalan pelayanan Bank Syariah SPM}

Keandalan pelayanan yang diberikan oleh bank spm yaitu pelayanan jeput bola Sehingga nasabah puas dengan pelayanan yang telah diberikan oleh bank spm pamekasan. Dalam keandalan pelayanan di bank SPM ini hasilnya sangat baik dan sesuai dengan bidangnya. ${ }^{19}$

\section{PEMBAHASAN}

\section{Strategi Kualitas Keandalan Pelayanan}

Ketersediaan fasilitas pelayanan kalau bicara tentang produk ini tidak jauh beda dengan bank lain atau koperasi lain. Dalam keandalan pelayanan apalagi karakter Madura ataupun nasabah yang tidak ingin ribet, tidak ingin menuggu lama dan nasabah pengen yang instan, dan yang instan ada di Bank SPM Pamekasan, karena nasabah yang tinggal duduk diam manis dirumahnya nasabah mau menabung tinggal menelfon atau melalui via whatshapp ataupun SMS. Nanti karyawan SPM mendatangi kerumahnya serta menyediakan mobil kas keliling dan bisa transaksi dan disitulah nasabah dipermudah tidak perlu membuang waktu untuk pergi ketempat SPM. ${ }^{20}$

\section{Strategi Mempertahankan Kepuasan Nasabah}

Bank SPM Pamekasan untuk mempertahankan kepuasan nasabah yaitu dengan memberikan pelayanan yang tidak membedakan status sosial pengguna jasa dan dengan begitu tidak ada keluhan dari pelayanan yang diterima oleh Bank SPM Pamekasan.

sedangkan untuk memahami harapan pelanggan yaitu diantara lain:

1) Jangan membuat nasabah merasa kecewa terhadap pelayanan yang telah diberikan.

2) Serta apa yang diperlukan atau apa yang dibutuhkan nasabah itu harus bisa melayaninya meski itu bukan urusan bank.

3) Dan harus memperhatikan nasabah dengan melalui Via SMS ataupun melalui telepon seluler atau bahkan main kerumahnya.

4) Dan juga harus menyanjung nasabah sekiranya pujian tersebut tidak berlebihan.

Bank SPM Pamekasan dalam memberikan pelayanan sesuai dengan hasil wawancara menyimpulkan bahwa pelayanan dapat memicu semangat kerja yang mana

\footnotetext{
18 Trisno Wahyudi, Marketing Funding Bank BPRS Sarana Prima Mandiri (SPM) Pamekasan, wawancara langsung (13 Oktober 2020).

${ }^{19}$ Ikbal, Kasi Funding Bank BPRS Sarana Prima Mandiri (SPM) Pamekasan, wawancara langsung (22 Oktober 2020).

${ }^{20} \mathrm{Ikbal}$, wawancara, (26 Oktober 2020)
} 
Bank SPM berusaha melengkapi fasilitas sarana dan prasarana didalam memberikan pelayanan.

\section{Kesimpulan}

Keandalan pelayanan yang diberikan oleh Bank SPM Pamekasan kepada masyarakat pelayanan jemput bola serta menyediakan mobil kas keliling sehingga nasabah merasa nyaman dengan pelayanan yang diberikan oleh Bank SPM. Dan pelayanan yang diberikan yaitu sudah cukup baik dan sesuai dengan bidangnya. Namun masih ada kekurang di Bank SPM yaitu masih belum ada ATM dan Bank SPM meningkatkan kualitas pelayanan menggunakan keandalan pelayanan. Sehingga nasabah puas dan tetap menjadi nasabah yang setia.

Sedangkan Strateginya dalam mempertahankan kepuasan nasabah bank SPM Pamekasan yang pertama yaitu meningkatkan kualitas pelayanan sehingga dapat mempermudah dan mempercepat pelayanan di bank SPM. Kedua, mengawasi kepuasan nasabah dengan melalui saran serta keluhan, Sehingga bisa dilakukan evaluasi serta perbaikan apabila ada pelayanan yang masih kurang baik.

\section{DAFTAR PUSTAKA}

Aliya, 2012. Strategi Pelayanan PT. Bank Bukopin TBK Dalam Meningkatkan Loyalitas Nasabah di makkasar ( Skripsi, Universitas Hasanuddin Makkasar)

Atep Adya Barata, 2003. Dasar-Dasar Pelayanan Prima (Jakarta: PT Elex Media Kompotindo Kelompok Gramedia)

Adi S. Widjojo dan Weman Suardy, Analisis strategi pelayanan Oleh Front Liner Dan Pengaruhnya Terhadap Kepuasan Nasabah PT. Bank Central Asia TBK Capen Mayor Okin, Jurnal Ilmiah Kesatuan, Vol.1 No.2, Oktober 2009 STIE.

Herry, E., Permana, P. Y. E., Aji, W. B., \& Muhtadi, R. (2019). Total Quality Management Development and Sharia Governance Efforts in Sharia Micro Financial Institutions to Improve Market Share. IJIEEB International Journal of Integrated Education, Engineering and Business eISSN 2615-1596 pISSN 2615-2312, 2(1), 27-35.

H.M Nasrullah Yusuf, 2014. Strategi Membangun Nilai Jasa Dan Kepercayaan Pelanggan (Yogyakarta Ed-1)

Ikbal,Wawancara, Selaku Funding di Bank SPM Pamekasan 10-Oktober-2020

Ikbal, Wawancara Selaku funding Di Bank SPM Pamekasan 22-Oktober-2020

Ikbal, wawancara, (26 Oktober 2020)

Kasmir, 2006 Kewirausahaan ,(Jakarta:Pt Raja Gransindo Persada) 
Lexy j, Moleong, 2012 Metodologi penelitian kualitatif ( Diterbitkan oleh PT REMAJA ROSDAKARYA Cetakan 31,)

M. Hamdani Pratama, Strategi Meningkatkan Kualitas Pelayanan Publik ( Studi Deskriptif tentang strategi UPTD Pengujian Kendaraan Bermotor Tandes Kota Surabaya Dalam Meningkatkan Kualitas Pelayanan Pengujian Kendaraan Bermotor ) Jurnal kebijakann dan manajemen publik Volume 3, No3, September-desember

Mansur, M. (2018). BANK SYARIAH: Antara Labelisasi dan Pemberdayaan Ekonomi Masyarakat. Ulumuna: Jurnal Studi Keislaman, 4(1), 54-70.

Muslikhin, M., Kinanti, R. A., Muhtadi, R., \& Fudholi, M. (2020). PEMERIKSAAN EMPIRIS PADA PENGARUH KINERJA SOSIAL TERHADAP PROFITABILITAS DI BANK SYARIAH. Ulumuna: Jurnal Studi Keislaman, 6(1), 72-84.

Nur Dwi Jayati, 2016. Kualitas pelayanan(Reabilitity, Responsiveness, Assurance, Emphaty, Tangibles) Di Legend Premium Coffee Yogyakarta. Skripsi, UN Yogyakarta.

Nur Ali, , 2017 Penilaian Kinerja Teller Pada PT. Bank Muamalat Indonesis Tbk. KCP Metro ,(Skripsi: Institut Agama Islam Negri,Metroz

Rosyadah, P. C., Arifin, N. R., Muhtadi, R., \& Safik, M. (2020). Factors That Affect Savings In Islamic Banking. AL-ARBAH: Journal of Islamic Finance and Banking, 2(1), 33-46

S.P Siaga.1994 Manejemen Modern,Jakarta:Masagung.

Sunyoto, 2004 Hamingpraja,Jaminan kualitas pelayanan konsumen. Penerbit Liberty,Yogyakarta.

Trisno Wahyudi, Marketing Funding Bank BPRS Sarana Prima Mandiri (SPM) Pamekasan, wawancara langsung (13 Oktober 2020). 